\title{
DISCRETE-TIME INTEGRAL SLIDING MODE CONTROL WITH DISTURBANCES COMPENSATION AND REDUCED CHATTERING FOR PV GRID-CONNECTED INVERTER
}

\author{
Santolo Meo — Vincenzo Sorrentino *
}

\begin{abstract}
In the paper a new discrete-time integral sliding mode control (DISMC) with disturbances compensation and reduced chattering for grid-connected inverter is proposed for active and reactive power regulation. Differently by many SMC proposed in literature that have a time-continuous formulation in spite have been implemented with digital processor, the proposed DISMC is fully formulated in discrete-time, taking into account the effects introduced by a microprocessor-based implementation. As will be demonstrated such approach consents to reduce the chattering about the sliding manifold within a boundary layer of $\mathrm{O}\left(\mathrm{T}^{2}\right)$ thickness instead of $O(T)$ (being $T$ the sampling period of the control algorithm). Moreover it introduces a correction of the control vector which eliminates the influence of modeling error and external disturbances improving stability and robustness of the controlled system. Constant converter switching frequency is achieved by using space vector modulation, which eases the design of the ac harmonic filter. In the paper, after a detailed formalization of the proposed control algorithm, several numerical and experimental results on a three-phase grid-connected inverter prototype are shown, proving the effectiveness of the control strategy.
\end{abstract}

K e y w or d s: sliding mode control, grid-connected inverter, renewable energy, PV inverter

\section{INTRODUCTION}

The PV market has grown over the past decade at a remarkable rate and it is on the way to become in prospective a major source of power generation for the world [1]. At the same time the research on the topic has been more and more increasing and the literature largely focused on the discussion about power inverter topologies and their control [2-7] and successively about smart-inverters [810]. Traditionally, grid-inverters do not provide ancillary services to the grid. Instead, main targets of the smart inverter are to maximize PV array output power ensuring highest possible efficiency and some ancillary services like the reactive power and voltage control, loss compensation, scheduling and dispatch, load following, system protection and so on.

Among these services the control of reactive power is of relevant importance and it can be easily given locally by the inverter based on the requests transmitted in real time by the network operator. Frequently the power converter interface from the dc source to the grid consists of a current controlled voltage source inverter (VSI). Classic control of grid-connected VSI is usually based on grid-voltage or virtual-flux $[11,12]$ oriented vector control schemes.

The scheme decomposes the ac currents into the synchronously rotating reference frame components. The power flow control is then achieved by regulating the decomposed converter currents. As current regulators are commonly used hysteresis, linear PI, predictive current control, state feedback current controller and so on [13$16]$.
Also different variable structure control (VSC) system have been proposed [17-19].

However these VSC controls neglect the effect of the microprocessor-based implementation, treating the system as if the control signals were available at every instant. Instead, in digital control power applications the control input is computed at discrete instants and applied to the system during the sampling interval. For this reason, inevitably, a nonideal sliding regime will appear having about the sliding manifold a chattering within a boundary layer of $O(T)$ thickness.

Moreover, this approach does not assure generally any convergence of the state trajectories onto the sliding manifold and may result in an increasing amplitude chatter of the state trajectories around the sliding manifold which means instability $[20,21]$. Consequently, an adequate discrete-time formulation of sliding mode control must be done. In order to overcome all the cited problems, in the paper a new discrete-time integral sliding mode control (DISMC) with disturbances compensation and reduced chattering for grid-connected inverter is proposed for active and reactive power regulation.

As it will be demonstrated such approach consents to reduce the chattering about the sliding manifold within a boundary layer of $\mathrm{O}\left(\mathrm{T}^{2}\right)$ thickness instead of $O(T)$.

Moreover it introduces a correction of the control vector which eliminates the influence of modeling error and external disturbances, improving stability and robustness of the controlled system also during the reaching phase, contrarily to the classic SMC that exhibits stability and robustness against parameter, line, and load uncertainties only after the occurrence of the sliding mode on the

\footnotetext{
* Department of Electrical Engineering and Information Technology, "Federico II" University, Via Claudio 21, Naples, Italy, santolo.meo@unina.it, vincenzo.sorrentino3@unina.it
} 


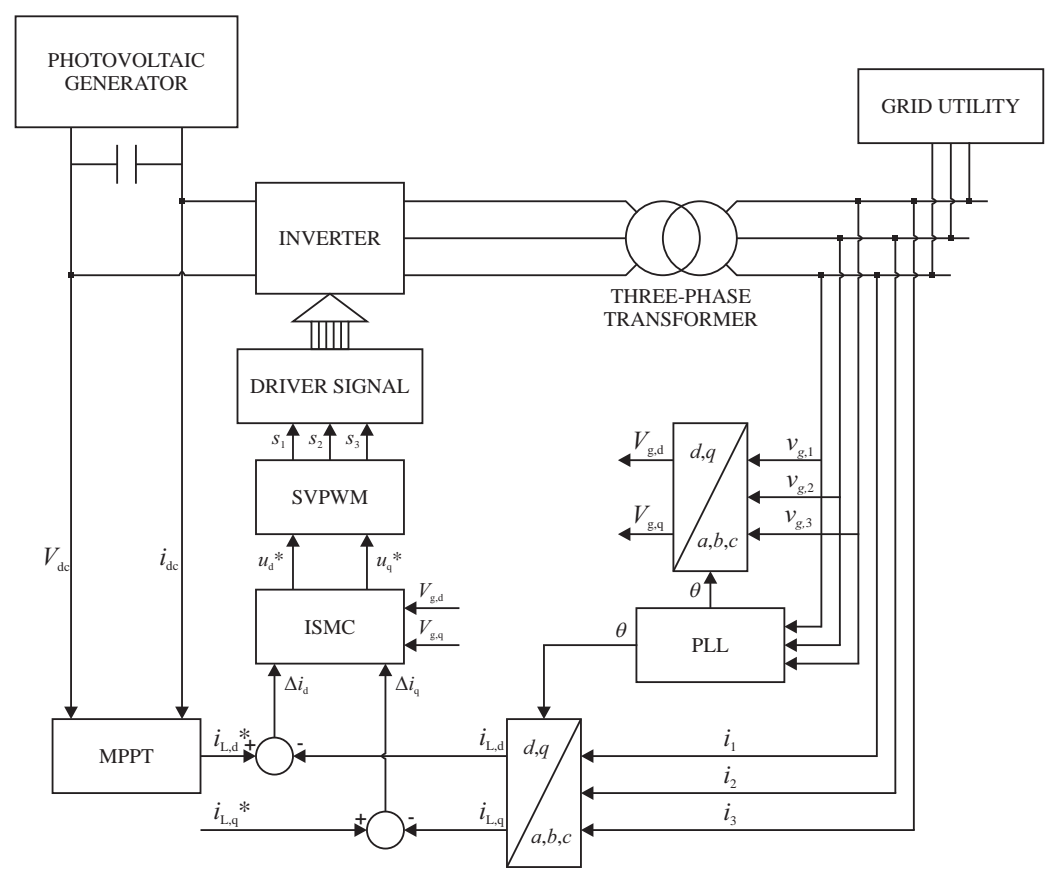

Fig. 1. Schema of the controlled system

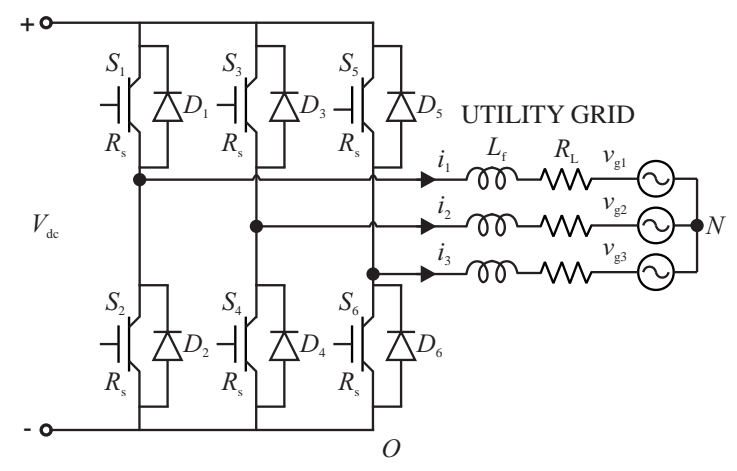

Fig. 2. Schema of the PVgrid-connected inverter

sliding manifold. In the paper the proposed control algorithm is fully developed in a rotating $d, q$ reference frame synchronous with the angular frequency of the grid and it is applied to control a grid-connected PV inverter in order to maximize the electrical energy produced by $\mathrm{PV}$ arrays and at the same time for using the grid-inverter as a reactive power compensator. An MPPT developed by the same Authors is adopted for tracking the maximum power point of the renewable source. After a detailed formalization of the proposed discrete-time ISMC some numerical and experimental results on a three-phase grid-connected inverter prototype are shown, proving the effectiveness of the control strategy. Thanks to the proposed control law the controlled system exhibits fast dynamic response, strong robustness to modeling error and uncertainties and good current harmonic rejection.

\section{DESCRIPTION OF THE CONTROLLED SYSTEM}

The considered controlled system is shown in Fig. 1. Its main parts are the power plant and the controller block. The power plant is composed by the PV arrays, the capacitors bank, the current controlled three phase VSI inverter, the filter inductance, the three-phase stepup transformer and current and voltage sensors on the DC link and on the grid. In the following the main components of the power plant will be depicted.

\subsection{The PV Array Characterization}

A full characterization of the PV output voltage (like function of the load request, of the irradiance and of the temperature) has been experimentally carried out. Then the experimental data have been interpolated with the well known following mathematical model of PV array

$$
V=\frac{A k \theta}{q} \ln \frac{I-I_{p h}-I_{s a t}}{I_{s a t}}-r_{s} I .
$$

PV array consists of $N_{s}$ cells in series formed the panel and of $N_{p}$ panels in parallel according to the rated power required.

The output voltage and current can be given by

$$
V_{d c}=N_{s}\left(V-r_{s} I\right), \quad I_{d c}=N_{p} I
$$

\subsection{Dynamic Model of the Voltage Source In- verter}

Referring to Fig. 2, the Kirchhoff voltage law applied to each phase yields (to simplify the analysis here, the transformer is neglected and only the filter inductance is considered)

$$
V_{d c} s_{k}-L_{f} \frac{\mathrm{d} i_{k}}{\mathrm{~d} t}-\left(R_{L}+R_{s}\right) i_{k}-v_{g, k}-V_{N O}=0,
$$

where $k=1,2,3$. 
Having assumed that the system is symmetrical and balanced, the application of the currents Kirchhoff law at node $\mathrm{N}$ gives

$$
V_{N O}=-\frac{V_{d c}}{3} \sum_{n=1}^{3} s_{n} .
$$

Substituting (5) in (4) it yields the following system of three differential equations

$$
L_{f} \frac{\mathrm{d} i_{k}}{\mathrm{~d} t}=V_{d c}\left(s_{k}-\frac{1}{3} \sum_{n=1}^{3} s_{n}\right)-R i_{k}-v_{g, k}
$$

where $R=\left(R_{L}+R_{s}\right)$.

Now the following complex vectors (space vectors) shall be defined

$$
\begin{gathered}
\mathbf{i}=\frac{2}{3} \sum_{k=1}^{3} i_{k} e^{j \frac{2 \pi}{3}(k-1)}, \quad \boldsymbol{u}=\frac{2}{3} V_{d c} \sum_{k=1}^{3} s_{k} e^{j \frac{2 \pi}{3}(k-1)} \\
\mathbf{v}_{g}=\frac{2}{3} \sum_{k=1}^{3} v_{g, k} e^{j \frac{2 \pi}{3}(k-1)}
\end{gathered}
$$

Multiplying both sides of (6) by $\frac{2}{3} e^{j \frac{2 \pi}{3}(k-1)}$ and summing over $k=1,2,3$ one gets the following vectorial differential equation

$$
L_{f} \frac{\mathrm{d} \mathbf{i}}{\mathrm{d} t}=\mathbf{u}-R \mathbf{i}-\mathbf{v}_{g}
$$

These space vectors are referred to a stationary reference frame. We can transform (8) from this stationary frame to a $d-q$ synchronous frame rotating at the angular frequency $\omega$ of the grid voltages and having the $d$-axis aligned with the $\boldsymbol{v}_{g}$ space vector. In such reference frame by separating the real and imaginary parts, (8) becomes

$$
\begin{aligned}
& L_{f} \frac{\mathrm{d} i_{d}}{\mathrm{~d} t}=u_{d}-R i_{d}-v_{g, d}+L_{f} \omega i_{q}, \\
& L_{f} \frac{\mathrm{d} i_{q}}{\mathrm{~d} t}=u_{q}-R i_{q}-v_{g, q}-L_{f} \omega i_{d} .
\end{aligned}
$$

\section{CONTROL DESIGN}

The controller block is composed by the MPPT control algorithm, by the integral sliding mode controller and the grid interface (Fig. 1). In the following the main components of the control system will be depicted.

\subsection{The Adopted MPPT Algorithm}

The input to the control strategy are the $d, q$ components $i_{d}^{*}$ and $i_{q}^{*}$ of the desired grid currents. The adopted MPPT algorithm controls the maximization of the input power and gives the values of the reference current $i_{d}^{*}$ in the synchronous reference-frame. The used MPPT is an improved version of the classic $\mathrm{P} \& \mathrm{O}$.

The improvement of the $\mathrm{P} \& \mathrm{O}$ algorithm has been obtained adjusting the perturbation width $(\Delta \mathrm{V})$ in function of the temperature. So, the dynamic response, when working conditions are far from the Maximum Power Point, can be improved without losing stability in the proximity of the Maximum.

It is well known that the voltage at which the power of a photovoltaic panel becomes maximum is almost independent on the solar irradiation but it is strongly dependent on the operating temperature.

For this reason the same author has proposed to adapt the perturbation width according to the temperature variations. In order to achieve this aim, a temperature modelling of the photovoltaic arrays has been used. The MPPT algorithm will not be treated in the following. A detailed description of such algorithm can be found in [22]. The reference component $i_{q}^{*}$ is computed according to the desired reactive power. For the calculation of these references the maximum apparent power of the threephase inverter is also considered.

When the PV system is not working at full power the three-phase inverter can also be working as reactive power compensator. Obviously the grid injected reactive power is limited by the maximum apparent power of the inverter.

\subsection{The Grid Interface}

The grid interface provides the synchronization with the grid voltages by means of a classical Phase-LockedLoop (PLL). The output of this block is necessary for the Park's transformation of the grid-voltages and of the grid-currents.

\subsection{Integral Sliding Mode Control (ISMC)}

The system of differential Equations (9) can be written in matrix form as follows (in balanced condition $v_{g, q}$ is null)

$$
\begin{gathered}
{\left[\begin{array}{c}
\frac{\mathrm{d} i_{d}}{\mathrm{~d} t} \\
\frac{\mathrm{d} i_{q}}{\mathrm{~d} t}
\end{array}\right]=\mathbf{A}\left[\begin{array}{c}
i_{d} \\
i_{q}
\end{array}\right]+\mathbf{B}\left[\begin{array}{l}
u_{d} \\
u_{q}
\end{array}\right]+\boldsymbol{c}} \\
\mathbf{A}=\left[\begin{array}{cc}
-\frac{R}{L_{f}} & \omega \\
-\omega & -\frac{R}{L_{f}}
\end{array}\right], \mathbf{B}=\left[\begin{array}{cc}
\frac{1}{L_{f}} & 0 \\
0 & \frac{1}{L_{f}}
\end{array}\right], \\
\boldsymbol{c}=\left[\frac{-v_{g, d}}{L_{f}}, \frac{-v_{g, q}}{L_{f}}\right]^{\top}
\end{gathered}
$$

$$
\begin{gathered}
x_{1}=i_{d}(t)-i_{d}^{*}(t), \quad x_{2}=i_{q}(t)-i_{q}^{*}(t), \\
\mathbf{x}=\left[\begin{array}{ll}
x_{1} & x_{2}
\end{array}\right]^{\top}
\end{gathered}
$$

The system of differential (10) can be re-writing with respect to the vector $\mathbf{x}$ giving

$$
\begin{aligned}
& \dot{\boldsymbol{x}}=\mathbf{A} \boldsymbol{x}+\mathbf{B} \boldsymbol{u}+\mathbf{D} \\
& \mathbf{D}=\boldsymbol{c}+\mathbf{A}\left[i_{d}^{*}, i_{q}^{*}\right]^{\top} .
\end{aligned}
$$


In (15) for taking into account modeling error and external disturbances (unbalanced conditions, voltage harmonics, sag and so on) we will consider the vector $\mathbf{z}$ depending on the time. $\boldsymbol{z}$ is assumed a smooth and bounded vector representing matched disturbances. It is unknown and will be estimated as depicted in the following. In this way the system (15) becomes

$$
\boldsymbol{x}=\mathbf{A} \boldsymbol{x}+\mathbf{B} \boldsymbol{u}+\boldsymbol{f}(t), \quad \boldsymbol{f}(t)=\mathbf{D}+\boldsymbol{z}(t) .
$$

The discrete-time formalization of the model (15), assuming zero-order hold on the control vector $\boldsymbol{u}$ can be given by

$$
\mathbf{x}_{k+1}=\mathbf{A}_{d} \mathbf{x}_{k}+\mathbf{B}_{d} \mathbf{u}_{k}+\boldsymbol{d}_{k}
$$

where

$$
\begin{aligned}
& \mathbf{A}_{d}=e^{\mathbf{A} T_{s}}, \quad \mathbf{B}_{d}=\int_{0}^{T_{s}} e^{\mathbf{A} \lambda} \mathbf{B} \mathrm{d} \lambda \\
& \boldsymbol{d}_{k}=\int_{0}^{T_{s}} e^{\mathbf{A} \lambda} \boldsymbol{f}\left((k+1) T_{s}-\lambda\right) \mathrm{d} \lambda \\
& \mathbf{a}_{K}=\mathbf{a}\left(k T_{s}\right), \quad \text { for } k=1,2,3 \ldots
\end{aligned}
$$

Firstly the objective of the SMC is to design a sliding manifold $\boldsymbol{\Sigma}$ so that the state trajectories of the system have the desired dynamic behavior. In particular the sliding manifold is generally defined as

$$
\boldsymbol{\Sigma}=\left\{\mathbf{x}_{k}: \boldsymbol{\sigma}_{k}=\boldsymbol{\sigma}\left(\mathbf{x}_{k}\right)=0\right\} .
$$

Considering the control vector $\boldsymbol{u} \in \Re^{m}$, the sliding manifold $\boldsymbol{\Sigma}$ represents the intersection of $m$ switching planes $\boldsymbol{\sigma}_{k, i}$, where $\boldsymbol{\sigma}_{k, i}=\left\{\mathbf{x}_{k}: \boldsymbol{\sigma}_{i}\left(\mathbf{x}_{k}\right)=0\right\}$, being $\boldsymbol{\sigma}_{i}$ the $i$-th row of the matrix $\boldsymbol{\sigma}_{k}$.

Now the problem is to find a switching vectorial function $\boldsymbol{\sigma}_{k}$ so that the motion of the dynamical system when confined on $\boldsymbol{\Sigma}$ is stable. Secondly, the problem is to find a variable structure control law so that, in finite time, the states are forced onto (sliding manifold reaching condition) and subsequently remain (convergence condition) on the sliding manifold $\boldsymbol{\Sigma}$ [23]. In classical DSMC the switching function $\boldsymbol{\sigma}_{k}$ is defined as

$$
\boldsymbol{\sigma}_{k}=\mathbf{K} \mathbf{x}_{k}
$$

In our case as switching function we adopt the proportional-integral functions with the errors among the $d, q$ components of the reference grid-currents and the actual ones. In other words let us define the switching function

$$
\boldsymbol{\sigma}_{k}=\mathbf{K} \boldsymbol{x}_{k}+\mathbf{H} T_{s} \sum_{\rho=0}^{k-1} \boldsymbol{x}_{\rho}
$$

where $\mathbf{K}$ and $\mathbf{H}$ are $m \times m$ matrices that will be chosen as depicted in the following.

The introduction of an integral action to the classical SMC has been adopted for overcoming the main drawback of the sliding mode control. As it is known the sliding mode control exhibits stability and robustness against parameter, line, and load uncertainties only after the occurrence of the sliding mode on the sliding manifold. On the contrary the Integral sliding mode consents to overcome this problem. Indeed with ISMC, the system trajectory always starts from the sliding surface.

Accordingly, the reaching phase is eliminated and robustness in the whole state space is obtained [23, 24].

Motion in sliding mode implies that

$$
\boldsymbol{\sigma}_{k+1}=0, \quad k=0,1,2,3, \ldots
$$

Substituting (24) into (25) yields

$$
\begin{gathered}
\boldsymbol{\sigma}_{k+1}=\mathbf{K} \mathbf{x}_{k+1}+\mathbf{H} T_{s} \sum_{\rho=0}^{k} \boldsymbol{x}_{k}=\boldsymbol{\sigma}_{k}+\mathbf{K}\left(\mathbf{x}_{k+1}-\mathbf{x}_{k}\right)+\mathbf{H} T_{s} \mathbf{x}_{k} \\
\mathbf{x}_{k+1}=\left(\mathbf{I}-\mathbf{K}^{-1} \mathbf{H} T_{s}\right) \mathbf{x}_{k}
\end{gathered}
$$

Equation (27) describes the system dynamic on the switching manifold. As can be noted the convergence velocity is independent of the system parameters, depending only on the matrices $\mathbf{K}$ and $\mathbf{H}$. Next step is to design the control law for the sliding-mode controller.

The control vector is structured as follows

$$
\boldsymbol{u}_{k}=\boldsymbol{u}_{e q, k}+\mathbf{u}_{s, k}
$$

Following the equivalent control method [23], we choice the so-called discrete-time equivalent control $\boldsymbol{u}_{e q, k}$ as the solution of (25). Substituting (26) and (19) in (25) and solving with respect to $\boldsymbol{u}_{k}$ yields

$$
\mathbf{u}_{e q, k}=-\left(\mathbf{K} \mathbf{B}_{d}\right)^{-1}\left[\left(\mathbf{K} \mathbf{A}_{d}+T_{s} \mathbf{H}-\mathbf{K}\right) \mathbf{x}_{k}+\mathbf{K} \boldsymbol{d}_{k}+\boldsymbol{\sigma}_{k}\right]
$$

Ideally, $\mathbf{u}_{e q, k}$ is a solution to the discrete-time sliding mode control because it maintains the state on the sliding manifold at each sampling instant. In addition, it is not a switching type of control law; hence, no chattering phenomenon would occur if only $\boldsymbol{u}_{e q, k}$ is employed.

Thanks to the application of the control vector $\boldsymbol{u}_{e q, k}$ the state vector starting from the initial point $\boldsymbol{x}_{0}$ reaches theoretically in one sampling time the sliding manifold.

Unfortunately, such result in practice is not possible for three main problems:

1) the implementation of (29) would require the a priori knowledge of the disturbance vector $\boldsymbol{d}_{k}$;

2) parametric uncertainties and exogenous perturbations can influence the modelling giving poor robustness to the control;

3) $\boldsymbol{u}_{e q, k}$ may exceed the available control resources tending to the infinity if the initial state is far from $\boldsymbol{\Sigma}$ or if the sampling period is small.

In order to the first problem, with some continuity assumption on the disturbances, $\boldsymbol{d}_{k}$ can be estimated by its previous value $\boldsymbol{d}_{k-1}[25]$. Let

$$
\hat{\boldsymbol{d}}_{k}=\boldsymbol{d}_{k-1}=\mathbf{x}-\mathbf{A}_{d} \mathbf{x}_{k-1}-\mathbf{B}_{d} \mathbf{u}_{k-1} .
$$


Equation (29) becomes

$$
\begin{aligned}
\mathbf{u}_{e q, k}=-\left(\mathbf{K B}_{d}\right)^{-1}\left[\left(\mathbf{K} \mathbf{A}_{d}\right.\right. & \left.+T_{s} \mathbf{H}\right) \mathbf{x}_{k}+\boldsymbol{\sigma}_{k}+ \\
& -\mathbf{K}\left(\mathbf{A}_{d} \mathbf{x}_{k-1}+\mathbf{B}_{d} \mathbf{u}_{k-1}\right] .
\end{aligned}
$$

The switching control vector $\boldsymbol{u}_{s, k}$ is therefore necessary to complete the reachability condition and to reduce the reaching time giving robustness to the control, avoiding the second problem. Such vector is generally chosen as

$$
\begin{gathered}
\boldsymbol{u}_{s, k}=-\left(\mathbf{K} \mathbf{B}_{d}\right)^{-1}\left[\mathbf{E} \operatorname{sign}\left(\boldsymbol{\sigma}_{k}\right)\right] \\
\operatorname{sign}\left(\boldsymbol{\sigma}_{k}\right)=\left[\operatorname{sign}\left(\boldsymbol{\sigma}_{k}(1,1)\right), \operatorname{sign}\left(\boldsymbol{\sigma}_{k}(2,1)\right)\right]^{\top}
\end{gathered}
$$

( $\mathbf{E}$ is a constant matrix with all non-negative elements).

Moreover it is necessary to take into account also the effective limits $u_{0}$ of the control (avoiding the third cited problem) imposing

$$
\begin{aligned}
& \left\|\mathbf{u}_{k}\right\| \leq u_{0}, \\
& \left\|(\mathbf{K B})^{-1}\right\|\left\|\left[\left(\mathbf{K} \mathbf{A}_{d}+T_{s} \mathbf{H}-\mathbf{K}\right) \mathbf{x}_{k}+\mathbf{K} \hat{\boldsymbol{d}}_{k}\right]\right\|<u_{0}
\end{aligned}
$$

(being $\left\|\boldsymbol{u}_{k}\right\|=\left(\boldsymbol{u}_{k}^{\top} \boldsymbol{u}_{k}\right)^{1 / 2}$ ) otherwise, the control resources are insufficient to stabilize the system.

For this reason the final variable structure control law will be

$$
\vec{u}_{k}= \begin{cases}\boldsymbol{u}_{e q, k}+\mathbf{u}_{s, k} & \text { for }\left\|\boldsymbol{u}_{e q, k}+\mathbf{u}_{s, k}\right\| \leq u_{0} \\ u_{0} \frac{\mathbf{u}_{k}}{\left\|\boldsymbol{u}_{k}\right\|} & \text { for }\left\|\boldsymbol{u}_{e q, k}+\mathbf{u}_{s, k}\right\|>u_{0}\end{cases}
$$

To guarantee the global stability of the sliding-mode control system is equivalent to guarantee sliding manifold reaching condition and the convergence condition.

Many literatures have been developed to deal with the problem of designing stable sliding manifold for continuous-time systems; on the contrary, the literature dealing with the problem of designing stable sliding manifold for discrete-time SMC is not wide.

Unfortunately, the sliding mode and reaching condition of the discrete VSC systems are different by those for continuous VSC systems. Generally, according to Lyapunov's theory, in the case of continuous-time systems, for example a sufficient condition so that the control system is stable and the system states can convergence to the sliding mode surface in the whole phase space is the verification of the following inequality:

$$
\boldsymbol{\sigma}^{\top} \dot{\boldsymbol{\sigma}}<0
$$

A continuous counterpart of the inequality (26) by means of simple equivalence obtained substituting the time-derivative by the forward difference is

$$
\boldsymbol{\sigma}_{k}\left(\boldsymbol{\sigma}_{k+1}-\boldsymbol{\sigma}_{k}\right)<0
$$

This condition, differently by the case of continoustime systems, is necessary but not sufficient for the existence of a discrete-time sliding motion [21]. Generally this condition does not assure any convergence of the state trajectories onto the sliding manifold and may result in an increasing amplitude chatter of the state trajectories around the sliding manifold which means instability [20].

A necessary and sufficient condition can be imposed assuring both sliding motion and convergence onto the sliding manifold. This condition may be stated as

$$
\left\|\boldsymbol{\sigma}_{k+1}\right\|<\left\|\boldsymbol{\sigma}_{k}\right\|
$$

The proposed variable structure control law satisfies banally the condition (38) in the case that $\left\|\boldsymbol{u}_{e q, k}\right\| \leq u_{0}$.

To prove the condition (38) we will consider the case $\left\|\boldsymbol{u}_{e q, k}\right\|>u_{0}$. Substituting (19), (28), (29) and (32) in (26) and taking into account (34), yields

$$
\begin{aligned}
& \boldsymbol{\sigma}_{k+1}=\left[\left(\mathbf{K} \mathbf{A}_{d}+T_{s} \mathbf{H}-\mathbf{K}\right) \boldsymbol{x}_{k}+\mathbf{K} \hat{\boldsymbol{d}}_{k}+\boldsymbol{\sigma}_{k}\right]\left(1-\frac{u_{0}}{\left\|\mathbf{u}_{k}\right\|}\right) \\
& -\mathbf{E} \operatorname{sign}\left(\boldsymbol{\sigma}_{k}\right) \frac{u_{0}}{\left\|u_{k}\right\|} \text {. }
\end{aligned}
$$

Thus

$$
\begin{array}{r}
\left\|\boldsymbol{\sigma}_{k+1}\right\| \leq\left\|\boldsymbol{\sigma}_{k}\right\|+\left\|\left[\left(\mathbf{K} \mathbf{A}_{d}+T_{s} \mathbf{H}-\mathbf{K}\right) \mathbf{x}_{k}+\mathbf{K} \hat{\boldsymbol{d}}_{k}\right]\right\| \\
-\frac{u_{0}}{\left\|(\mathbf{K B})^{-1}\right\|} \leq\left\|\boldsymbol{\sigma}_{k}\right\| .
\end{array}
$$

Hence $\left\|\boldsymbol{\sigma}_{k+1}\right\|$ decreases monotonically and after a finite numbers of sampling times the states are forced onto and subsequently remain on the sliding manifold.

Therefore is proved that the proposed control law (35) satisfies the inequality (38) and guarantees the convergence and the global stability of the solution.

Finally, in order to assure a fast convergence it is fundamental the choice of a suitable values in the matrices $\mathbf{K}$ and $\mathbf{H}$.

In particular if $\boldsymbol{\sigma}_{k} \in \mathbb{R}^{m}, \mathbf{x}_{k} \in \mathbb{R}^{n}, \mathbf{K}$ and $\mathbf{H}$ are constant matrices of rank $m$ and they are chosen such that $[24]$

1) $\mathbf{K} \mathbf{B}_{d}$ is an invertible matrix;

2) $\mathbf{H}=-\mathbf{K}\left[\mathbf{A}_{d}-I-\mathbf{B}_{d} \mathbf{G}\right]$ where $\mathbf{G}$ is a matrix so that the poles of the matrix $\mathbf{A}_{d}-\mathbf{B}_{d} \mathbf{G}$ are distinct and within the unit circle.

At end in the following we will prove the reduced chattering achieved with the proposed control.

If the system is in sliding mode for $t=k T_{s}$ (25) is verified.

Now we must evaluate the thickness of the boundary layer of the sliding manifold in the intersampling istant $t=k T_{s}+\tau$ where $0 \leq \tau \leq T_{s}$ for evaluating the maximum deviation of the state by the sliding manifold.

For the time-continuous system (19) if a switching function like (24) is adopted, the dynamic equation for the sliding surface vector $\boldsymbol{\sigma}=0$ is

$$
\dot{\boldsymbol{\sigma}}=\mathbf{K} \dot{\mathbf{x}}+\mathbf{H} \mathbf{x}=\mathbf{K}(\mathbf{A} \mathbf{x}+\boldsymbol{f}(t))+\mathbf{H} \mathbf{x}+\mathbf{K B u} .
$$


Let us consider the system (19) and the sliding surface (41), considering the intersample instant $t=k T_{s}+\tau$ and integrating both sides of (41) from $k T_{s}$ to $k T_{s}+\tau$, it yields (42)

$\boldsymbol{\sigma}\left(k T_{s}+\tau\right)=\boldsymbol{\sigma}_{k}+\int_{k T_{s}}^{k T_{s}+\tau}[\mathbf{K}(\mathbf{A x}+\boldsymbol{f}(t))+\mathbf{H} \mathbf{x}+\mathbf{K B} \boldsymbol{u}] \mathrm{d} t$.

Considering that in discrete-time SMC the control law is a piecewise constant function therefore $\boldsymbol{u}(t)=\boldsymbol{u}_{k},(42)$ becomes

$\boldsymbol{\sigma}\left(k T_{s}+\tau\right)=\boldsymbol{\sigma}_{k}+\int_{k T_{s}}^{k T_{s}+\tau}[\mathbf{K}(\mathbf{A} \mathbf{x}+\boldsymbol{f}(t))+\mathbf{H} \mathbf{x}] \mathrm{d} t+\tau \mathbf{K} \mathbf{B} \mathbf{u}_{k}$.

Substituting (29) into (43) and considering that in sliding mode $\boldsymbol{\sigma}_{k+1}=\boldsymbol{\sigma}_{k}=0$ (43) yields

$$
\begin{array}{r}
\boldsymbol{\sigma}\left(k T_{s}+\tau\right)=\int_{k T_{s}}^{k T_{s}+\tau}[\mathbf{K}(\mathbf{A} \boldsymbol{x}+\boldsymbol{f}(t))+\mathbf{H} \boldsymbol{x}] \mathrm{d} t- \\
\tau(\mathbf{K B})\left(\mathbf{K} \mathbf{B}_{d}\right)^{-1}\left[\left(\mathbf{K} \mathbf{A}_{d}+T_{s} \mathbf{H}-\mathbf{K}\right) \mathbf{x}_{k}+\mathbf{K} \hat{\boldsymbol{d}}_{k}\right] .
\end{array}
$$

Because both the state $\boldsymbol{x}$ and the disturbance $\boldsymbol{f}$ are smooth and bounded, the integrations in (44) can be approximated by using Euler's method (45)

$$
\begin{aligned}
\int_{k T_{s}}^{k T_{s}+\tau} & {\left[\mathbf{K}(\mathbf{A} \mathbf{x}+\boldsymbol{f}(t))+\mathbf{H}_{\mathbf{x}}\right] \mathrm{d} t=} \\
\tau & {\left[\mathbf{K}\left(\mathbf{A x}\left(k T_{s}\right)+\boldsymbol{f}\left(k T_{s}\right)\right)+\mathbf{H}_{\mathbf{x}}\left(k T_{s}\right)\right]+O\left(\tau^{2}\right) . }
\end{aligned}
$$

In similar way after the application of the Euler's method and the Taylor's series expansion of $\mathbf{A}_{d}, \boldsymbol{d}_{k}$ and having truncated $\mathbf{B}_{d}$ to the first term we get

$$
\begin{aligned}
& \mathbf{A}_{d}=\mathbf{I}+\mathbf{A} T_{s}+O\left(T_{s}^{2}\right) ; \mathbf{B}_{d}=\mathbf{B} T_{s}+O\left(T_{s}^{2}\right) ; \\
& \boldsymbol{d}_{k}=T_{s} \boldsymbol{f}\left((k+1) T_{s}-t\right)+O\left(T_{s}^{2}\right)=T_{s} \boldsymbol{f}\left(k T_{s}\right)+O\left(T_{s}^{2}\right)
\end{aligned}
$$$$
(\mathbf{K B})\left(\mathbf{K} \mathbf{B}_{d}\right)^{-1}\left[\left(\mathbf{K} \mathbf{A}_{d}+T_{s} \mathbf{H}-\mathbf{K}\right) \mathbf{x}_{k}+\mathbf{K} \hat{\boldsymbol{d}}_{k}\right]=
$$$$
\left[\mathbf{K A} \mathbf{x}_{k}+\mathbf{H} \mathbf{x}_{k}+\mathbf{K} \boldsymbol{f}\left(k T_{s}\right)\right]+O\left(T_{s}^{2}\right) \text {. }
$$

Defining the new variables

$$
\begin{array}{r}
q_{1}=\int_{k T_{s}}^{k T_{s}+\tau}[\mathbf{K}(\mathbf{A} \mathbf{x}+\boldsymbol{f}(t))+\mathbf{H} \mathbf{x}] \mathrm{d} t \\
-\tau\left[\mathbf{K}\left(\mathbf{A} \mathbf{x}\left(k T_{s}\right)+\boldsymbol{f}\left(k T_{s}\right)\right)+\mathbf{H} \mathbf{x}\left(k T_{s}\right)\right], \\
q_{2}=(\mathbf{K B})\left(\mathbf{K} \mathbf{B}_{d}\right)^{-1}\left[\left(\mathbf{K} \mathbf{A}_{d}+T_{s} \mathbf{H}-\mathbf{K}\right) \mathbf{x}_{k}+\mathbf{K} \hat{\boldsymbol{d}}_{k}\right] \\
-\left[\mathbf{K A} \mathbf{x}_{k}+\mathbf{H}_{k}+\mathbf{K} \boldsymbol{f}\left(k T_{s}\right)\right]
\end{array}
$$

and substituting (48) and (49) into (44) yields

$$
\boldsymbol{\sigma}\left(k T_{s}+\tau\right)=q_{1}-\tau q_{2} \leq O\left(T_{s}^{2}\right) .
$$

Thus, it is proved that with a discrete-time formalization of the controlled system and with an integral sliding mode control even if the state is kept exactly in the sliding manifold $\boldsymbol{\Sigma}$ at each sampling period, the intersample behavior deviates from $\boldsymbol{\Sigma}$ by an amount $O\left(T^{2}\right)$ which is lower than what can be achieved adopting by a direct implementation of the time-continuous modelling in a sampled-data system or adopting a classical SMC, that instead have thickness $O(T),[25]$. This demonstration is quite different by [24].

\section{SIMULATION RESULTS}

In order to verify the performance of the proposed control strategy based on the ISMC approach, some simulations have been developed using MATLAB/Simulink. Discrete models were used with a simulation step time of $1 \mu \mathrm{s}$. The electric parameters of the tested system are listed in Table 1.

The PV generator has been simulated as depicted in the section 2.1 and was connected to the grid-inverter block. A space vector PWM with a sampling frequency of $20 \mathrm{kHz}$ was used.

Figure 3 shows the grid-voltage, the grid-current and the actual and reference currents $i_{d}, i_{d}^{*}$ and $i_{q}, i_{q}^{*}$. The reference component $i_{d}^{*}$ is step-changed at $0.132 \mathrm{~s}$ from $12.4 \mathrm{~A}$ (corresponding to a active power of $6 \mathrm{~kW}$ ) to $6.2 \mathrm{~A}$ (corresponding to a active power of $3 \mathrm{~kW}$ ) during a time of $300 \mu \mathrm{s}$ and then backed to $12.4 \mathrm{~A}$ at $0.1723 \mathrm{~s}$ during the same time of $300 \mu \mathrm{s}$, while the reference reactive power is contextually fixed to zero $\left(i_{q}^{*}=0\right)$. For representing on the same figure also the phase grid voltage and the grid current the zero of the reference components $i_{d}^{*}$ and $i_{q}^{*}$ has been translated to the value of $-15 \mathrm{~A}$ on the ordinate axis. As can be noted the current is always in phase with the voltage and exhibits a very fast response.

Figure 4 shows the grid-voltage, the grid-current and the actual and reference currents $i_{d}, i_{d}^{*}$ and $i_{q}, i_{q}^{*}$. The reference component $i_{q}^{*}$ is step-changed at $0.132 \mathrm{~s}$ from $0 \mathrm{~A}$ to $6.2 \mathrm{~A}$ (corresponding to a reactive power of $3 \mathrm{kVA}$ ) during a time of $300 \mu \mathrm{s}$ and then backed to $0 \mathrm{~A}$ at $0.1723 \mathrm{~s}$ during the same time of $300 \mu \mathrm{s}$, while the reference active power is contextually fixed to $6.2 \mathrm{~A}$ (corresponding to a active power of $3 \mathrm{~kW}$ ).

For representing on the same figure also the phase grid voltage and the grid current the zero of the reference components $i_{d}^{*}$ and $i_{q}^{*}$ has been translated to the value of $-15 \mathrm{~A}$ on the ordinate axis. As can be noted the current is initially in phase with the voltage then, in correspondence of the reference change rapidly presenting a phase change of $45^{\circ}$. In all the simulation the ripple on the current is very low.

In order to prove the robustness of the proposed control again the modeling error and external disturbances a 5 -th and 7-th harmonic have been added to the threephase sinusoidal grid-voltage; moreover the inductance $L_{F}$ has been reduced of 10 times respect to the values implemented in the control algorithm and $R_{L}$ has been incremented 10 times respect to the values implemented in the control algorithm. Figure 5 shows the simulation results.

The reference component $i_{d}^{*}$ is fixed to $6.2 \mathrm{~A}$ (corresponding to an active power of $3 \mathrm{~kW}$ ) and $i_{q}^{*}$ is contextually fixed to zero. As can be noted even though the strong parametric modelling and disturbance errors the response of the system is very good. 


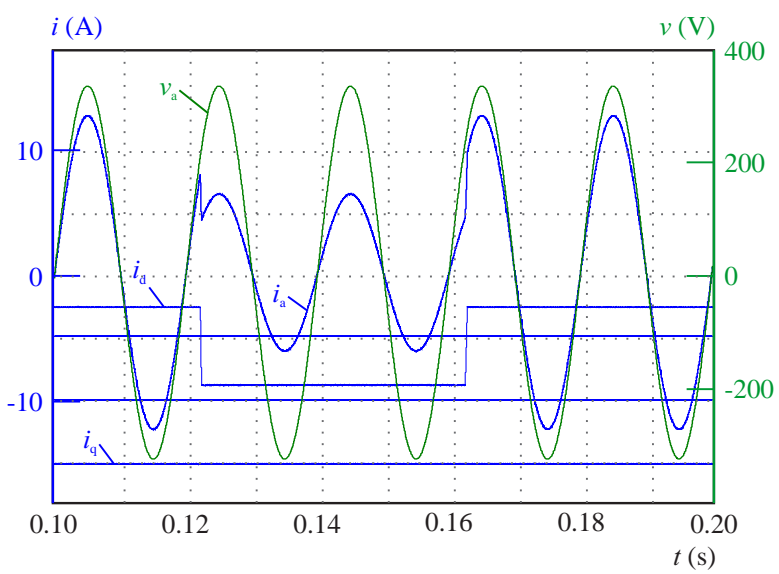

Fig. 3. Grid-voltage and grid-current, actual and reference currents $i_{d}^{*}$ and $i_{q}^{*}$ for a step change of $i_{d}^{*}$

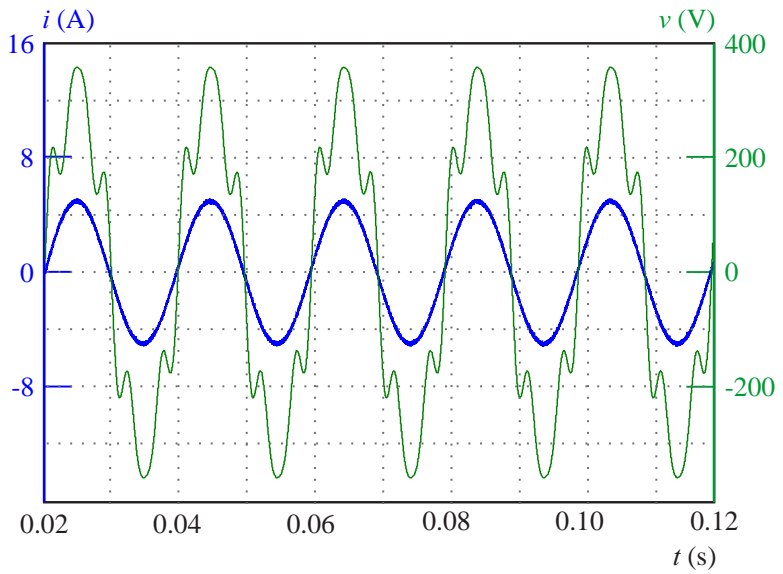

Fig. 5. Grid-voltage and grid-current, when modelling error and external disturbances are considered

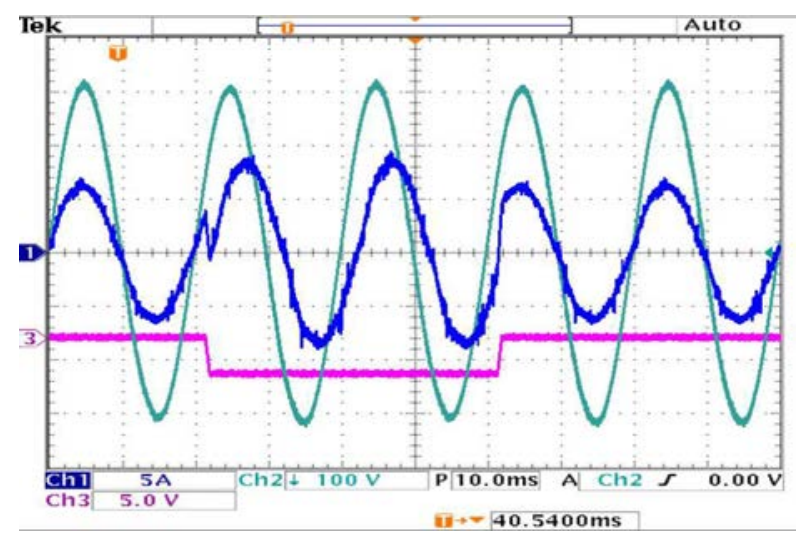

Fig. 7. Grid-voltage and grid-current, actual and reference currents $i_{d}$ and $i_{q}$ for a step change of $i_{q}^{*}$

\section{EXPERIMENTAL RESULTS}

In order to validate the performances of the proposed control strategy an experimental prototype has been arranged. The control strategy has been developed in MATLAB/SIMULINK and implemented on DSP dSPACE1103 Motorola PowerPC 60K $333 \mathrm{MHz}$.

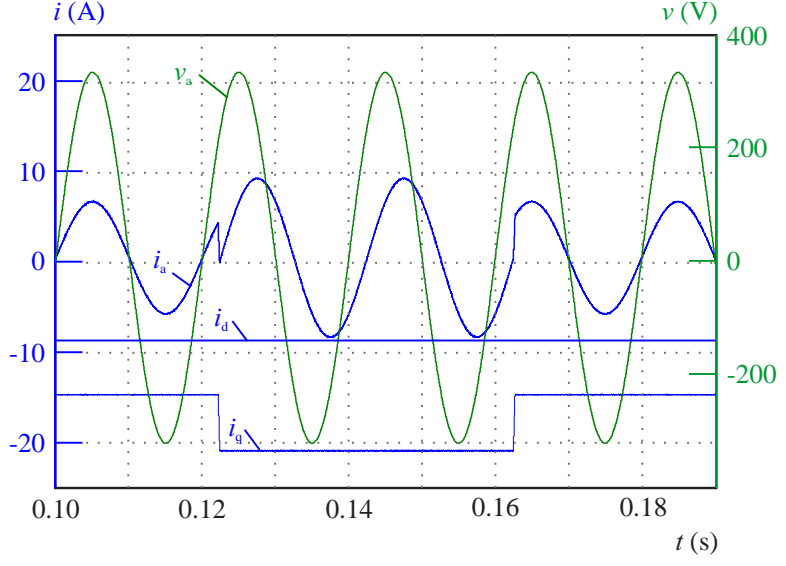

Fig. 4. Grid-voltage and grid-current, actual and reference currents $i_{d}^{*}$ and $i_{q}^{*}$ for a step change of $i_{q}^{*}$

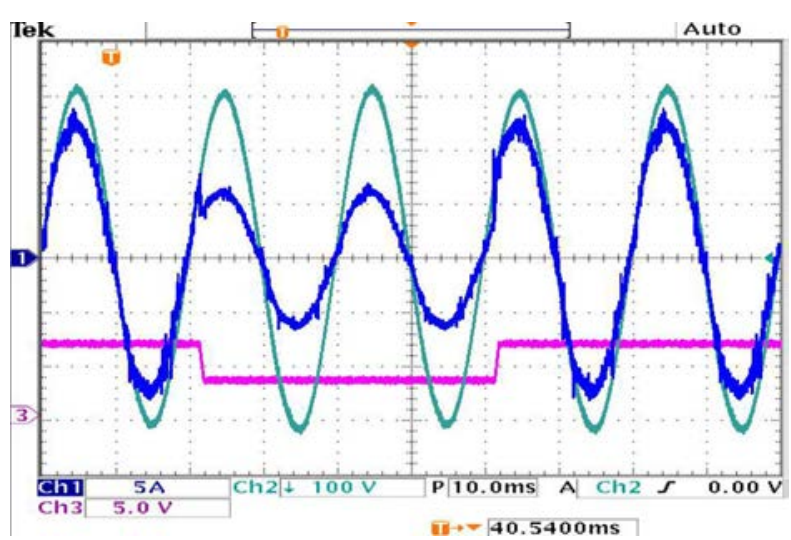

Fig. 6. Grid-voltage and grid-current, actual and reference currents $i_{d}$ and $i_{q}$ for a step change of $i_{d}^{*}$



Fig. 8. Grid-voltage and grid-current, when modelling error and external disturbances are considered

The dSPACE1103 is a well known all-rounder in rapid control prototyping. A graphical user interface has been developed using the Control Desk software by dSPACE in order to control the converter and to monitor the electrical variables of the PV inverter. The main specifications of the experimental prototype are listed in the Table 1. 
Table 1. Specifications of the experimetal prototype

\begin{tabular}{|c|c|c|}
\hline \multicolumn{2}{|c|}{ Components } & Rating values \\
\hline \multicolumn{3}{|c|}{$\begin{array}{l}\text { PV generator } \\
\text { (MITSUBISHI ELECTRIC PV) }\end{array}$} \\
\hline \multicolumn{2}{|c|}{$\begin{array}{l}10 \text { strings connected in serie. Each } \\
\text { string is composed of } 6 \text { modules in } \\
\text { parallel ( } 170 \mathrm{Wp} \text { per module })\end{array}$} & $\begin{array}{c}10 \mathrm{kWp}, 246 \mathrm{~V}, \\
42 \mathrm{~A}(@ S T C)\end{array}$ \\
\hline \multicolumn{3}{|c|}{ PV module (PV-MF170EB4) } \\
\hline \multicolumn{2}{|l|}{ Rating power $\left(P_{p}\right)$} & $170 \mathrm{Wp}$ \\
\hline \multicolumn{2}{|c|}{$I_{s c}($ short circuit current $)$} & $7.38 \mathrm{~A}$ \\
\hline \multicolumn{2}{|c|}{$V_{o c}($ open circuit voltage) } & $30.6 \mathrm{~V}$ \\
\hline \multicolumn{2}{|l|}{$V_{M}(\mathrm{MPP}$ voltage $)$} & $24.6 \mathrm{~V}$ \\
\hline \multicolumn{2}{|l|}{$I_{M}(\mathrm{MPP}$ current $)$} & $6.93 A$ \\
\hline \multicolumn{2}{|c|}{ Temperature coefficient of $V_{o c}$} & $-0.346 \% /{ }^{\circ} \mathrm{C}$ \\
\hline \multicolumn{2}{|c|}{ Temperature coefficient of $I_{s c}$} & $+0.057 \% /{ }^{\circ} \mathrm{C}$ \\
\hline \multicolumn{2}{|c|}{ Temperature coefficient of $P_{p}$} & $-0.478 \% /{ }^{\circ} \mathrm{C}$ \\
\hline $\begin{array}{l}\text { IGBT/Inverter } \\
\text { Module }\end{array}$ & $\begin{array}{l}\text { SEMIKRON } \\
3 \times S K M 50 \\
\text { GB 123D } \\
\end{array}$ & $\begin{array}{l}1200 \mathrm{~V}-50 \mathrm{~A} \\
\left(@ 25^{\circ} \mathrm{C}\right)\end{array}$ \\
\hline$C_{P V}$ & \multicolumn{2}{|c|}{$\begin{array}{l}\text { DC Capacitor bank - } \\
\text { Electrolytic } \\
2 \mathrm{x} 2200 \mu \mathrm{F} / 400 \mathrm{~V} \text { in series } \\
\text { total equivalent capacitance } \\
1100 \mu \mathrm{F} / 800 \mathrm{~V} \\
\end{array}$} \\
\hline$L_{F}, R_{L}, R_{s}$ & $\begin{array}{l}\text { Grid side } \\
\text { inductor and } \\
\text { resistence }\end{array}$ & $4 \mathrm{mH}, 10 \mathrm{~m} \Omega$ \\
\hline \multicolumn{3}{|c|}{$\begin{array}{l}\text { GRID POWER } \\
\text { TRANSFORMER }\end{array}$} \\
\hline
\end{tabular}

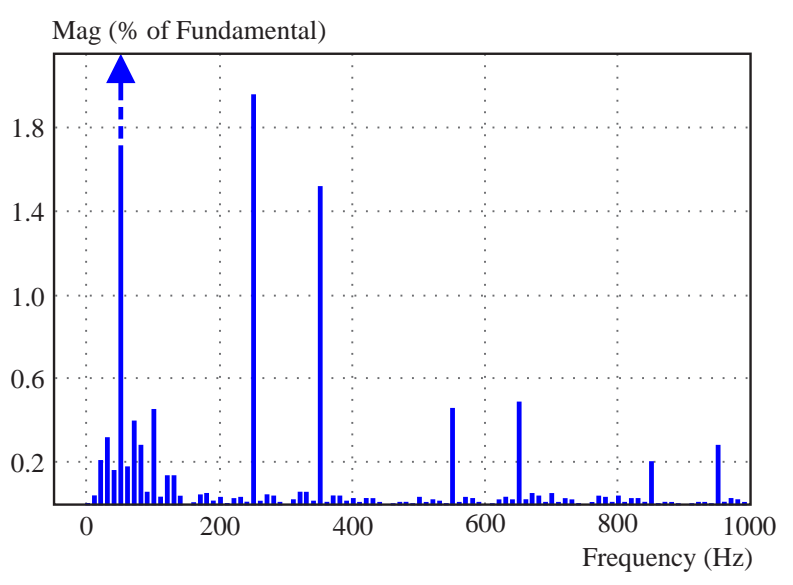

Fig. 9. Steady state grid-current harmonic spectra

Figures 6, 7 and 8 show the experimental response of the controlled system in the same operative conditions depicted in Figs 3, 4 and 5. Only the time scale is different and it can be deduced by the figures. As can be seen from the waveforms in Figs. 6, 7 and 8 compared with Figs. 3, 4 and 5 the experimental results are in well accordance with the simulated ones. Figure 9 illustrates the grid-current harmonic spectra. Each harmonic amplitude is expressed in percentage of the amplitude of the fundamental. The THD is $4.03 \%$.

In all the considered operative conditions the current chattering on the references components of the grid currents has been always within $\pm 0.02 \mathrm{~A}$. It is not shown in the figures only for space saving.

\section{CONCLUSION}

In the paper a new discrete-time integral variable structure control of grid-connected PV inverter is proposed in order to maximize the input power given by $\mathrm{PV}$ arrays and at the same time for using the grid-inverter as a reactive power compensator.

The proposed VSC is fully formulated in discretetime, taking into account the effects introduced by a microprocessor-based implementation and it introduces respect to the classical formalization of the VSC an integral action that improve the performance of the controlled system and a correction of the control vector which eliminates the influence of modeling error and external disturbances. Thanks to the proposed control law the controlled system exhibits fast dynamic response, strong robustness and good current harmonic rejection.

\section{Nomenclature}

$I_{p h} \quad$ Light generated current

$I_{\text {sat }} \quad$ Saturated reverse current

$q \quad$ Electronic charge

$A \quad$ p-n junction ideality factor

$K \quad$ Boltzmann constant

$\theta \quad$ Temperature in Kelvin degrees

$r_{s} \quad$ Series resistance

$V_{d c} \quad$ PV array voltage

$I_{d c} \quad$ PV array current

$s_{k}, s_{n} \quad$ Gating signals

$R_{s} \quad$ IGBT's on-state resistance

$L_{f}, R_{L} \quad$ Filter inductance and equivalent series resistance (ESR) of the filter inductor

$i_{k}, i_{d}, i_{q} \quad$ Grid currents (for $k=1,2,3$ ) and their components in $d, q$ reference-frame

$v_{g, k}, v_{g, d}, v_{g, q}$ Grid voltages (for $k=1,2,3$ ) and their

$\mathbf{A}^{\top} \quad$ Transpose of the matrix $\mathbf{A}$

$T_{s} \quad$ Sampling period

\section{REFERENCES}

[1] MASSON, G.-ORLANDI, S.-REKINGER, M. : Global Market Outlook for Photovoltaics 2014-2018, European Photovoltaic Industry Association (EPIA), June 2014. 
[2] YANG, Y.-ENJETI, P.-BLAABJERG, F.-WANG, H. : Suggested Grid Code Modifications to Ensure Wide-Scale Adoption of Photovoltaic Energy in Distributed Power Generation Systems, in 2013 IEEE Industry Applications Society Annual Meeting, 2013, pp. 1-8.

[3] LIU, L.-LI, H.-XUE, Y.-LIU, W.: Decoupled Active and Reactive Power Control for Large-Scale Grid-Connected Photovoltaic Systems Using Cascaded Modular Multilevel Converters, IEEE Transactions on Power Electronics 30 No. 01 (2015), 176-187.

[4] KARUPPUSAMY, P.-NATARAJAN, A. M.: Neuro Fuzzy Controller for Grid Connected Photovoltaic System with Multilevel Inverter, International Review on Modelling and Simulations (IREMOS) 6 No. 03 (2013), 693-705.

[5] VALAN RAJKUMAR, M.-MANOHARAN, P. S.: Harmonic Reduction of Fuzzy PI Controller based Three-Phase Seven-Level DCMLI with SVPWM for Grid Connected Photovoltaic System, International Review on Modelling and Simulations (IREMOS) 6 No. 03 (2013), 684-692.

[6] ESSEFI, R. M.-SOUISSI, M.-ABDALLAH, H. H. : Current control strategy for grid connected photovoltaic inverter via LCL filter, International Review on Modelling and Simulations (IREMOS) 6 .

[7] DAmiAno, A.-GATTO, G.-MARONGIU, I.-MEO, S.PERFETTO, A.-SERPI, A. : Single-Stage Grid Connected PV Inverter with Active and Reactive Power Flow Control via PSO-PR based Current Controlled SVPWM, International Review of Electrical Engineering (IREE) 7 No. 04 (2012), 4647-4654.

[8] FERNAOPIRES, V.-MARTINS, J. F.-SILVA, J. F. : A Control Structure for a Photovoltaic Supply System with Power Compensation Characteristics Suitable for Smart Grid Topologies, 8th International Conference on Compatibility and Power Electronics, 2013, pp. 40-45.

[9] HAN, Y.: Passivity-Based Control Scheme for the Modular Multilevel Cascaded Converter (MMCC) as the HVDC-PLUS for Smart Grid Applications, International Review of Electrical Engineering (IREE) 8 No. 02 (2013), 558-567.

[10] HASHMI, M.-HANNINEN, S.-MAKI, K. : Developing Smart Grid Concepts, Architectures and Technological Demonstrations Worldwide - a Literature Survey, International Review of Electrical Engineering (IREE) 8 No. 01 (2013), 236-252.

[11] KAZMIERKOWSKI, M. P.-MALESANI, L. : Current Control Techniques for Three-Phase Voltage-Source PWM Converters: A Survey, IEEE Transactions on Industrial Electronics 45 No. 05 (1998), 691-703.

[12] HU, J.,-ZHU, J.-DORRELL, D. G.-GUERRERO, J. M. : Virtual Flux Droop Method, A New Control Strategy of Inverters in Microgrids, IEEE Transactions on Power Electronics 29 No. 09 (2014), 4704-4711.

[13] YANG, B.-WU, J.-LU, X.-HE, X. : An Improved DSP-based Control Strategy with Predictive Current Control and Fuzzy Voltage Control for Grid-Connected Voltage Source Inverters, Industrial Electronics, IECON 2008. 34th Annual Conference of IEEE, 2008, pp. 2296-2300.

[14] ZARE, F.-LEDWICH, G. : A New Hysteresis Current Control for Three-phase Inverters Based on Adjacent Voltage Vectors and Time Error, Power Electronics Specialists Conference, 2007, pp. 431-436.

[15] BLORFAN, A.-STURTZER, G.-FLIELLER, D.-WIRA, P.-MERCKLE, J. : An Adaptive Control Algorithm for Maximum Power Point Tracking for Photovoltaic Energy Conversion
Systems - A Comparative Study, International Review of Electrical Engineering (IREE) 9 No. 03 (2014), 559-565.

16] TARIK, J.-ABDERRAHMANE, E. K.-NABIL, E. H.-ABDELHAMID, N.: New Control based on Estimated State Feedback of the Shunt Active Filter to Compensate for the Disturbing Currents in the Electric Power, International Review on Modelling and Simulations (IREMOS) 7 No. 03 (2014), 457-465.

17] HU, J.-SHANG, L.-HE, Y.-ZHU, Z. Q. : Direct Active and Reactive Power Regulation of Grid-Connected DC/AC Converters Using Sliding Mode Control Approach, IEEE Transactions on Power Electronics 26 No. 01 (2011), 210-222.

18] GUISSER, M.-EL-JOUNI, A.-ABDELMOUNIM, E. H. : Robust Sliding Mode MPPT Controller based on High Gain Observer of a Photovoltaic Water Pumping System, International Review of Automatic Control (IREACO) 7 No. 02 (2014), $225-232$.

19] MEO, S.-SORRENTINO, V.-ZOHOORI, A.-VAHEDI, A. : Second-Order Sliding Mode Control of a Smart Inverter for Renewable Energy System, International Review of Electrical Engineering (IREE) 9 No. 06 (2015), 1090-1096.

20] SARPTURK, S. Z.-ISTEFANOPULOS, Y.-KAYNAK, O. : On the Stability of Discrete-Time Sliding Mode Control Systems, IEEE Transaction on Automatic Control 32 No. 10 (1987), 930-932.

21] ILOSAVLJEVIC, D.: General Conditions for the Existence of a Quasi-Sliging Mode on the Switching Hyperplane in Discrete Variable Structure System, Automat. Remote Contr. 46 (1985), 307-314.

[22] ESPOSITO, F.-ISASTIA, V.-MEO, S.-PIEGARI, L. : An Improved Perturbe and Observe Algorithm for Tracking Maximum Power Points of Photovoltaic Power Systems, International Review on Modelling and Simulations (IREMOS) 0 No. 00 (2008), 10-16.

[23] UTKIN, V.-GULDNER, J.-SHIJUN, M. : Sliding Mode Control in Electromechanical Systems, Taylor \& Francis, 1999.

[34] ABIDI, K.-XU, J. X.-XINGHUO, Y. : On the Discrete-Time Integral Sliding Mode Control, IEEE Trans. Autom. Control 52 No. 04 (2007), 709-715.

25] SU, W. C.-DRAKUnOV, S.-OZGUNER, U.: An O(T $\left.{ }^{2}\right)$ Boundary Layer in Sliding Mode for Sampled-Data Systems, IEEE Trans. Autom. Control 45 No. 03 (2000), 482-485.

Received 8 September 2014

Santolo Meo (SMIEEE '08) received BS and MS degrees with honours from FEDERICO II University of Naples, Italy, where currently he is an associate professor. His current research interests include the fields of power electronics and electrical drives. He is the author of about 130 scientific publications on journals and international conferences in the power electronics field. He is Editor-in-chief of the International Review of Electrical Engineering (IREE) and of the International Review on Modelling and Simulations (IREMOS).

Vincenzo Sorrentino was born in Naples, Italy on February 26,1986 . He received the BS and MS. degrees in electrical engineering, magna cum laude, from the Federico II University of Naples. He is currently a $\mathrm{PhD}$ student in electrical engineering at the Department of Elettrical Engineering and Information Technologies (DIETI) of the Federico II University of Naples. His research focuses on design and control of power electronic systems for the grid integration of renewable energy sources. 